\title{
SQUAMOUS-CELL CARCINOMA OF THE URINARY BLADDER
}

\author{
ALBERT J. SCHOLL, JR., M.D. \\ Fellow in Urology, Mayo Foundation \\ ROCHESTER, MINN.
}

Various investigators have shown that columnar and transitional epithelial linings in certain organs of the body are capable of extensive epidermization when a protective covering is desirable. Broders ${ }^{1}$ has found a transition from a columnar to a squamous covering in everted, prolapsed irritated uteri. Rokitansky ${ }^{2}$ describes a stage of epidermoid metaplasia of the mucous membrane of the urinary bladder as cholesteatoma. Kretschmer ${ }^{3}$ collected from the literature the reports of forty-four cases of leukoplakia of the bladder, ureter, and pelvis of the kidney, showing that the urinary tract, normally lined by transitional epithelium, is capable of developing a squamous-cell surface. The traumatized exposed surfaces of extrophied bladders practically always show areas of epidermization.

Halle ${ }^{4}$ holds that this epithelial transformation of the mucosa of the urinary passages results from chronic inflammation, either simple or due to stones. He reports seven such cases in the bladder, in all of which there was cystitis; in four there were stones. Similar cases, associated with calculi, are reported by Cabot, ${ }^{5}$ Nogués $^{6}$ and Verriére. ${ }^{7}$. Albarran ${ }^{8}$ mentions the occurrence of epidermization following longstanding cystitis. Morris ${ }^{9}$ describes the conversion, under prolonged irritation, of the lining of a ureter, which for a long time had been the resting place of calculi, to a thick and wrinkled membrane which histologically was divisib'e into cutis vera and epidermis. While thronic

1. Broders, A. C.: Personal communication.

2. Rokitansky, C.: A Manual of Pathologic Anatomy, Philadelphia, Blanchard and Lea, 1:306, 1855 .

3. Kretschmer, H. L. : Leukoplakia of the Bladder and Ureter, Surg, Gynec. \& Obst. 31:325-339 (Oct.) 1920.

4. Hallé, N.: Leucoplasies et cancroides dans l'appareil urinaire, Ann. d. mal. d. org. génito-urin. 11:481, 577, 1895.

5. Cabot, A. T.: A Case of Cystitis with the Formation of a Thick Epidermal Sheet in the Bladder, Am. J. M. Sc. 101:135-142, 1891.

6. Nogués, P.: Trouble des urines du la présence exclusive des cellules epitheliales, Ann. d. mal. d. génito-urin. 17:585-589, 1899

7. Vierriére, A.: Deux cas de leucoplasie de la muceuse vésicale, Lyon méd. 95: $116-125,1910$.

8. Albarran, J.: Les tumeurs de la vessie, Paris, Steinheil, 1892.

9. Morris, H.: Surgical Diseases of the Kidney and Ureter, London, Cassell. 2: 1901 . 
irritation is a common cause of the condition, it is not an essential factor in all cases. Leber ${ }^{10}$ reports the case of an infant of 4 months in whom the epithelial lining of the pelvis of the kidney was composed of many layers of cells showing cornification; a similar condition was found in the infant's eye. This case suggests a congenital origin. Lecene ${ }^{11}$ holds that the process in these cases is due, not to chronic inflammation, but to developmental changes in the genito-urinary tract. IIilson ${ }^{12}$ suggests that epidermoid growths of the pelvis of the kidney may be due to inclusions of ectodermal cells carried from the rectum to the kidney by way of the cloacal wall. Malignant transformation of this epidermized epithelium is not an uncommon event. According to Fwing, ${ }^{13}$ squamous metaplasia which affects the cells before the tumor develops accounts for the presence of epidermoid carcinoma in unusual

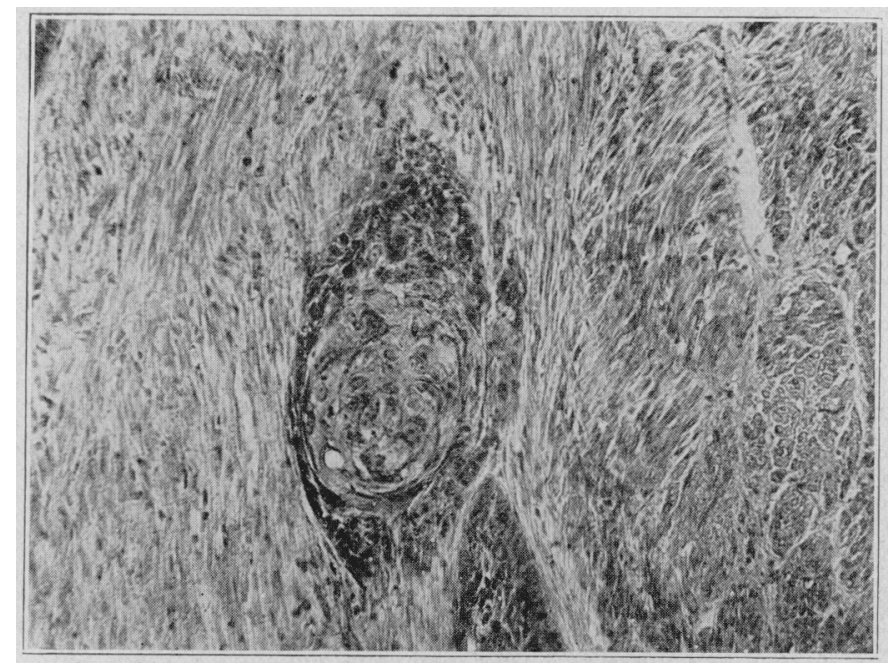

Fig. 1 (Case 2, 147667).- Isolated malignant focus with epithelial pearl growing hetween muscle bundles in the resical wall; $\times 100$.

situations. Typical squamous-cell carcinoma, which has all the characteristics of this disease on the cutaneous surface, is occasionally found in the genito-trinary tract.

10. Leher. T.: Ueber die Xerosis der Bindehant und die infantile Hornhautverschwärung nebst Bemerkungen üler dic Entstehung des Xerophthalmus (Abstract). Deutsch. med. Wchnschr. 10:206, 1884.

11. Lecène, P.: Un cas de leucoplasic du hassinet, J. d'urol. méd. et chir. 1:129-137, 1913.

12. Wilson, L. B.: The Embryogenetic Relationships of Tumors of the Kidney, Suprarenal, and Testicle, Ann. Surg. 57:522-535, 1913.

13. Ewing, J.: Neoplastic Diseases, a Textlook on Tumors, Philadelphia, W. B Saunders Company, 1919. 
Albarran ${ }^{14}$ notes that vesical leukoplakia may become transformed into true epidermoid cancer. Hallé ${ }^{4}$ also is of the opinion that these tumors become engrafted on epidermized plaques. Buerger, ${ }^{15}$ in describing squamous-cell tumors of the bladder, states that the mucous membrane in the immediate neighborhood of ten shows leukoplakia. A number of squamous-cell carcinomas of the ureter and of the pelvis of the kidney have been described. Kischensky ${ }^{16}$ cites a case of squamous-cell epithelioma of the pelvis of the kidney with extensive metaplastic changes in the surrounding tissues and extending down the ureter into the bladder.

Primrose ${ }^{17}$ reported a case of squamous-cell carcinoma of the renal pelvis complicated by a stone in a horse shoe kidney. Scheel ${ }^{18}$

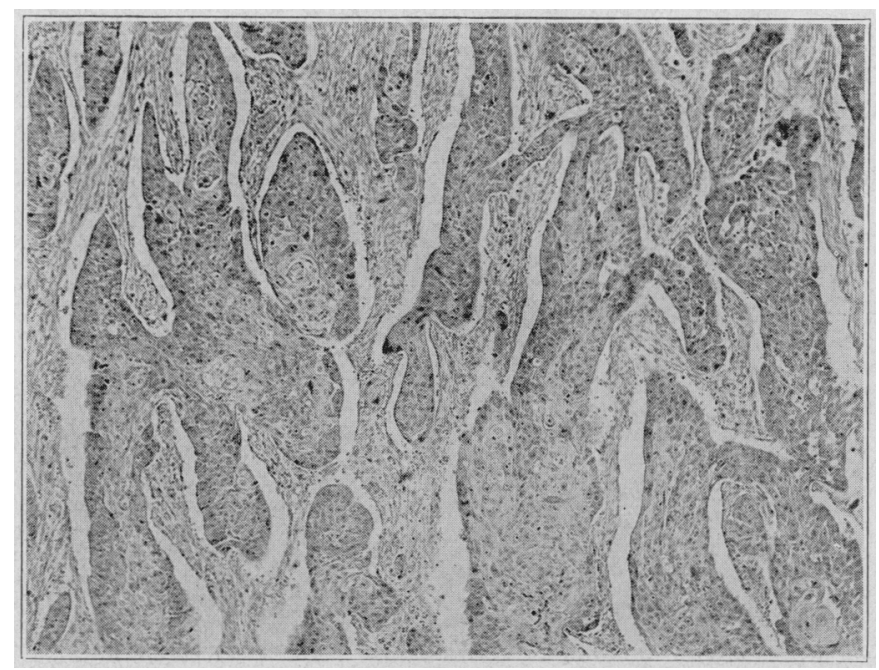

Fig. 2 (Case 3, 203917).-Wide spread extension of tumor masses through the outer layers of the wall of the bladder; $\times 50$.

describes a combination of papilloma and squamous-cell epithelioma of the pelvis of the kidney with multiple metastases. The metastases

14. Albarran, J.: Neoplasmes primitifs du bassinet et de l'uretere, Ann. d. mal. d. org. génito-urin. 18:918-954, 1900.

15. Buerger, L.: The Pathological Diagnosis of Tumors of the Bladder with Particular Reference to Papilloma and Carcinoma, Surg., Gynec. \& Obst. 21: 179-198. 1915.

16. Kischensky, D. P.: Primärer Plattenepithelkrebs ler Nierenkelche und Metaplasie des Epithels der Nierenkelche, des Nierenbeckens und des Ureters, Bietr. z. path. Anat. u. z. allg. Path. 30:348-369, 1901.

17. Primrose, A.: Squamous-Cell Carcinoma of the Kidney, J. A. M. A. $75: 12$ ( July 3) 1920.

18. Scheel, P. F.: Leber ein eigenartiges Kankro:d der Niere, Virchows Arch. f. path. Anat. 201:311-325, 1910 . 
showed only cells of the squamous type. In 195 tumors of the kidney observed at the Mayo Clinic there was one squamous-cell carcinoma of the pelvis of the kidney. Garceau ${ }^{19}$ cites a case of Adlers of epidermoid carcinoma of the ureter. Rundle ${ }^{20}$ also describes a very extensive tumor of this type originating in the lower end of the ureter and markedly infiltrating the surrounding tissues and metastasizing to the liver and lungs.

Cases of epidermoid carcinoma of the bladder are not uncommon. Albarran found four cases in a review of 125 cases of vesical tumor. Three of the patients died very shortly after operation; one was well four months later. Halle collected the reports of a number of cases from the literature and gives the history of four patients observed at

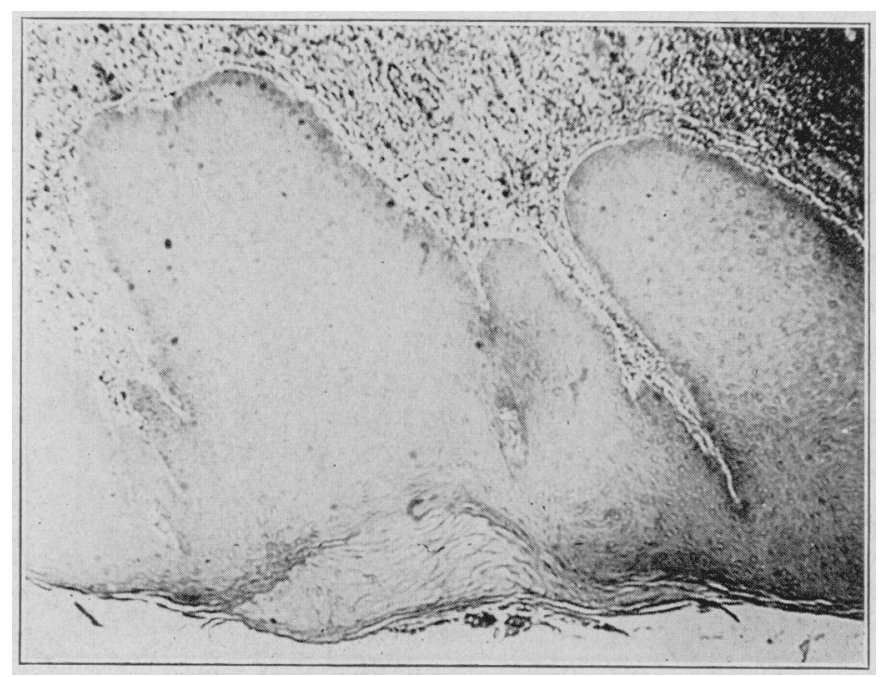

Fig. 3 (Case 3, 203917).-Epidermization of mucosa in regions adjoining squamous-cell carcinoma; $\times 50$.

the Necker hospital. In three of these four patients the condition was inoperable; the patients died shortly after entering the hospital. The fourth patient was operated on and died immediately after the operation. Montfort ${ }^{21}$ collected seven cases: in three, there was an extension to the rectum; in a fourth, the growth had spread through the dome of the bladder, a mass "the size of an apple" being found in the

19. Garceau, E.: Tumors of the Kidney, New York, D. Appleton \& Co., 1909.

20. Rundle, H.: Epithelioma of the Ureter Causing Hydronephrosis, Tr. Path. Soc., London, 47:128-132, 1896.

21. Montfort, E.: Rôle de la prostate dans la production des tumeurs epitheliales infiltrées de la vessie, Thèse, Paris, Rousset, 1903. 
adherent great omentum. Montfort states that in all his cases the tumor was complicated by marked cystitis. Of 113 neoplasms of the bladder, Buerger ${ }^{15}$ regarded five as squamous-cell carcinoma. $\mathrm{He}$ states that they rapidly penetrate the muscular coats and that they offer a very poor prognosis for the patient. Fenwick ${ }^{22}$ cites two cases, one in which a benign papilloma was surrounded by a dense squamouscell epithelioma. There was marked infiltration of the wall of the bladder, the vesical surface being flat and necrotic. The second case was that of an extremely large tumor arising from the posterior wall of the bladder and having a history of only six months' duration. Geraghty ${ }^{23}$ states that squamous-cell carcinoma is exceedingly rare.

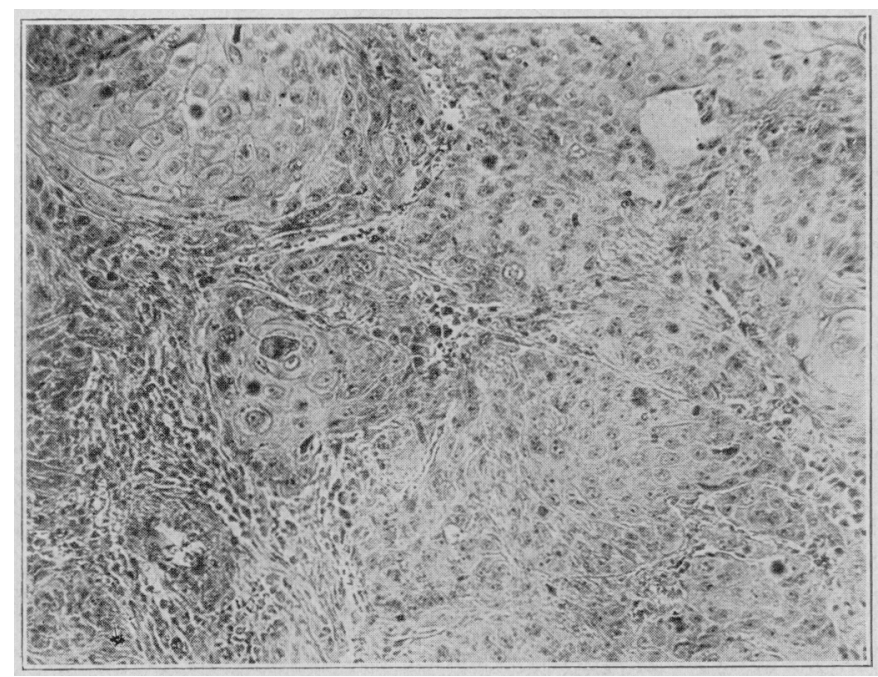

Fig. 4 (Case 3, 203917) - Solit masses of tumor cells with many epithelial pearls. A number of malignant cells show two or even three decply staining ntucleoli : $\times 100$.

He found only one case in 180 epithelial tumors of the bladder observed in Johns Hopkins Hospital. Busse ${ }^{24}$ describes a case associated with a papillomatous growth in the ureter and extensive metastases. Cassanello ${ }^{2:}$ reports two cases, in one of which the his-

22. Fenwick, E. H.: A Handbook of Clinical Electric-Light Cystoscopy, London, Churchill, 1904.

23. Geraghty, J. T.: Quoted by Cabot H.: Modern Urology, in Original Contributions by American Authors, Philadelphia, Lea and Febiger, 1918.

24. Busse, O.: Geschwulstbildung in den grossen Harnwegen, Virchows Arch. f. path. Anat. 164:119-132, 1901 .

25. Cassanello, R.: Contributo allo studio dell' epithelioma epidermoidale della vesica con speciale riguardo all question del chorion epithelioma vesicae, Folia urolog. 3:509-540, 1909 . 
tologic structure of the growth greatly resembled a chorio-epithelioma. He states that the growth in his cases was very malignant, rapidly and extensively infiltrating the surrounding tissues.

The majority of squamous-cell carcinomas of the bladder are flat and ulcerated, extensively involving the wall. The preoperative symptoms are generally of short duration. In most cases the symptoms are mild and do not give a correct indication of the extent of the condition. Metastases occur, but not so frequently nor so extensively as the extent and appearance of the local lesion would indicate. Squamous-cell tumors, in general, especially those showing marked differentiation, do not metastasize readily. The metastases in most cases are confined to the local lymph areas. Sanderson ${ }^{26}$ has observed a case of squamous-cell epithelioma of the penis, with metastases to the inguinal nodes. Five years later there had been no further metastases.

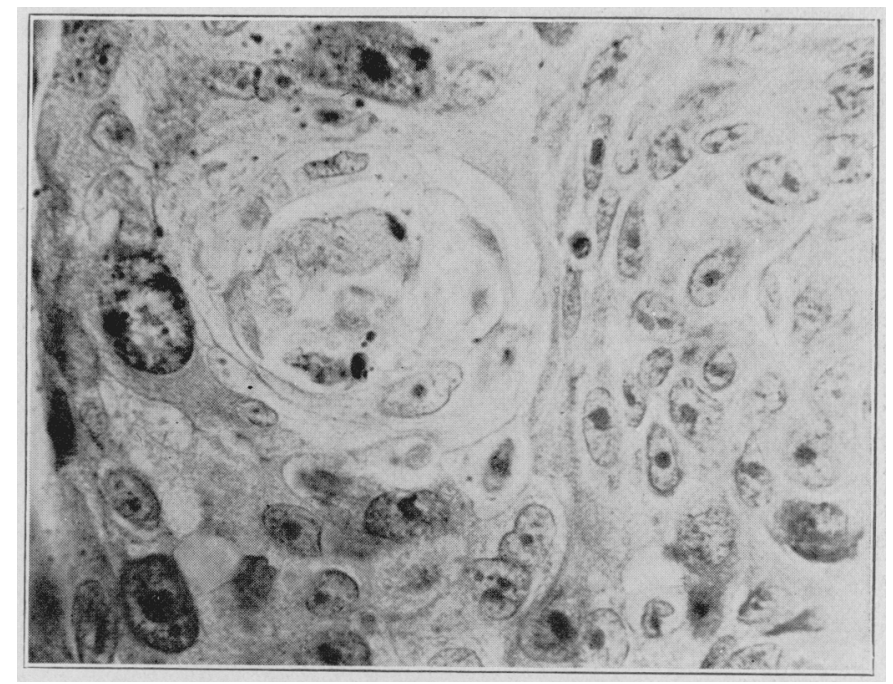

Fig. 5 (Case 3, 203917).-Atypical mitotic figures, irregularity in size and staining qualities of cells and large deeply staining nucleoli, "one-eyed malignant cells" (Broders) ; $\times 500$.

Mitotic figures are fairly common in epidermoid tumors of the bladder, but they do not always indicate a high degree of malignancy. Broders ${ }^{1}$ holds that mitotic figures are not so important a criterion of malignancy in epithelioma as they are in connective tissue tumors. Evans $^{2 \pi}$ showed that in sarcoma and myosarcoma the malignancy varied directly with the number of mitotic figures. Broders has seen

26. Sanderson, F. R.: Personal communication.

27. Evans, N.: Malignant Myomata and Related Tumors of the Uterus, Surg.. Gynec. \& Obst. 30:225-239 (March) 1920. 
patients with epithelioma of the penis with numerous mitotic figures alive and well three years after operation in contrast to other patients in whom mitotic figures were rare who died shortly after operation from recurrence of tumor.

Six cases of squamous-cell epithelioma in 333 neoplasms of the bladder were observed in the Mayo Clinic from Jan. 1, 1910, to Jan. 1, 1920. These six cases are of interest not only because of their extreme malignancy, but because of the insidious onset and the lack of definite symptoms. The growths are readily recognized histologically, and this is of distinct prognostic importance.

CASE 1 (60036).-Mrs. M. P., aged 45, came to the clinic, Oct. 13, 1911, because of frequent attacks of hematuria during the last four months. She had not had pain but had lost 30 pounds in weight in the four months.

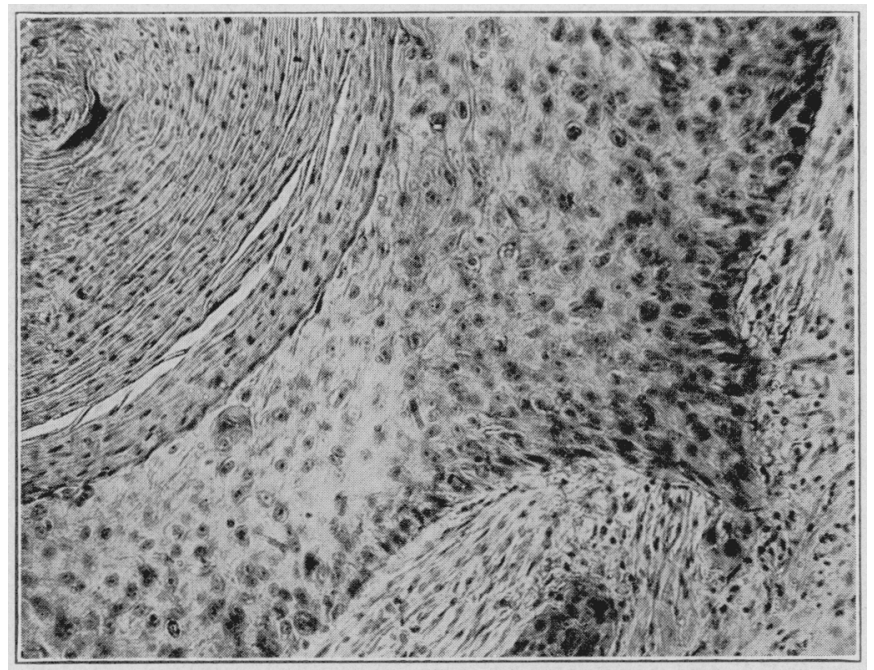

Fig. 6 (Case 5, 313258).-Wide spread hyalinization, showing layered cleavage planes of hornified areas; $\times 100$.

The general physical examination was negative. The cystoscopic examination showed a flat nodular growth $3 \mathrm{~cm}$. in diameter on the upper left wall of the bladder. At operation an indurated broad base carcinoma was found, and a transperitoneal resection of the upper third of the bladder was performed. The patient readily recovered from the operation. She returned to the clinic two years later with a small recurrent growth which was removed by fulguration. Seven years after fulguration and nine years after operation she is well, and has no signs or symptoms of recurrence.

The excised tumor was rough, flat, firm, and friable, $2 \mathrm{~cm}$. by $3 \mathrm{~cm}$., and extended down, out into surrounding submucous tissues. It was covered by keratinized tissue $3 \mathrm{~mm}$. thick. This readily flaked off. Histologic examination revealed a typical squamous-cell carcinoma. It consisted of branching columns and large solid masses of only moderately differentiated epithelial cells. The 
cells, in the main, were large, irregular, pale and unevenly stained, with prominent nucleoli. In the larger masses the peripheral cells were smaller and more deeply stained. The central or older cells showed degenerative changes and in some areas were arranged in circular whorls of completely hyalinized cells-the so-called epithelial pearls. A few areas showed a tendency toward papillomatous formation, the cells arranging themselves around a connective tissue axis and assuming a palisade formation. Large masses and strands of malignant cells projected into the submucous and muscular tissue and at times isolated epithelial pearls were seen pressed between muscular and fibrous bands. There was a marked round-cell infiltration, mostly plasma cells, not only throughout the malignant area but also in the submucous and muscular coats of the bladder. A large number of mitotic figures, the lack of cellular differentiation, and the irregularity and varying size of the cells, with the local extension, indicated a high degree of malignancy.

CASE 2 (147668).-Mrs. W. B., aged 54, was examined in the clinic, Dec. 10, 1915. She had been troubled with frequency of micturition and periodic

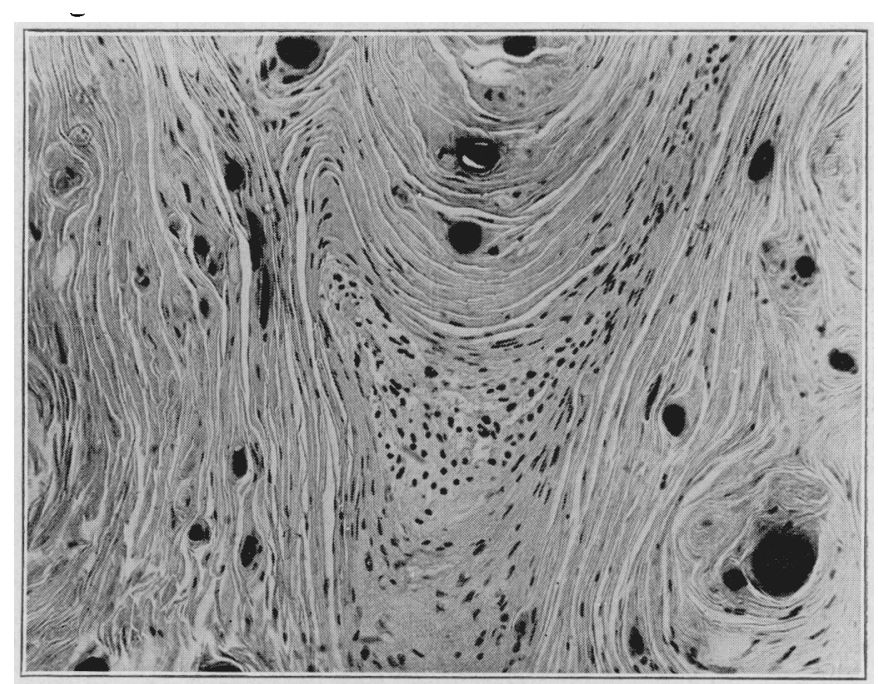

Fig. 7 (Case 5, 332791).-Extreme hyalinization of tumor masses; $\times 100$.

irritability for twenty-eight years. The urinary trouble started directly after a difficult childbirth. Twenty-four years before examination she had had several attacks of severe pain in her right loin; the last one had occurred twenty years before. For the last three years, frequency and dysuria had been slight and infrequent. Two months before there had been a marked exacerbation of the urinary trouble and a slight terminal hematuria. The recent bladder trouble was more severe and "different" from that of the last twenty-eight years.

On physical examination, a hard, tender mass $4 \mathrm{~cm}$. in diameter was felt in the suprapubic region. Cystoscopy revealed a flat growth $6 \mathrm{~cm}$. in diameter on the right half and dome of the bladder. At operation an extensive indurated tumor was found extending from the dome to the right base. A transperitoneal extirpation of the right half of the bladder was performed and the right ureter ligated. The patient convalesced satisfactorily. Four months later, a small recurrence of the tumor was fulgurated. After two months, the recurrence 
persisting, the bladder was reopened and thrce small growths cauterized. Six months later, one year after the irst operation, the patient died from recurrence.

The tumor was $5 \mathrm{~cm}$. in diameter; its surface was ulcerated. It involved the entire wall of the bladder, and in one area it extended to the peritoneum. In places the growth was fibrous and dry with a tendency to split along cleavage planes, as is often seen in papillary carcinomas. Microscopic examination revealed in certain areas a high degree of differentiation with extensive hyalinization and pearly body formation (Fig. 1). In other areas the cells were large, irregular, and active with no tendency toward epidermization. There wers many mitotic figures and a moderate round-cell intiltration.

CASE 3 (203917).-Mr. W. A. P., aged 32. came to the clinic, Aug. 4, 1917, because of pain in the lower right abdomen, and moderate frequency and dysuria of three months duration. During this time he had lost 20 pounds in weight. Cystoscopy revealed a necrotic mass $6 \mathrm{~cm}$. in diameter on the dome of the bladder. It operation a large carcinoma of the dome and posterior wall was discovered. The mucosa of the remainder of the wall of the bladder

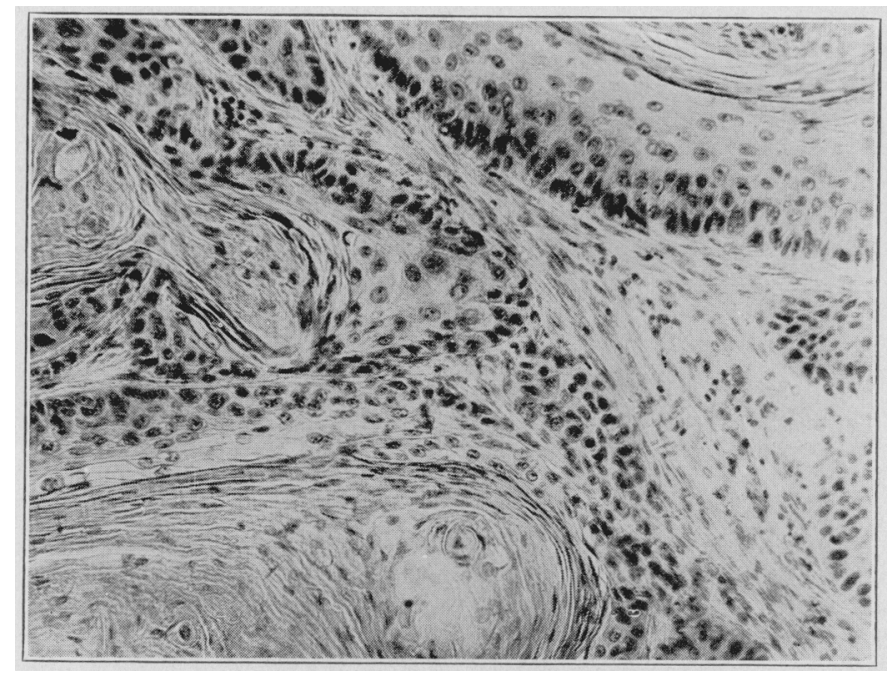

Fig. 8 (Case 6. 332791).-Extensive pearly lody formation with many rapidly growing malignant cells; $\times 100$.

was moderately necrotic. A transperitoneal resection of the upper third of the bladder was performed. The patient recovered tiormally, but died six montls later from extensive local recurrence.

The tumor was flat and firm with an ulcerated necrotic surface $6 \mathrm{~cm}$. in diameter. The sides sloped ontward to meet the mucosa of the bladder, the infiltration extending deeply into the muscular coats. In one section the neighboring mucosa was covered by an area of letkoplakia. The histologic examination revealed marked round-cell intiltration. The cells were only slightly differentiated, although onlỵ moderate pearly body formation was seen. The individual cells were partly hylinized in a few areas and retained their rounded contours, large nuclei, and prominent nucleoli. There was marked connective tissue reaction; in some sections this completely isolated parts of the tumor (Figs. 2, 3, 4 and 5). 
Case 4 (305220).-Mrs. S. R. P., aged 31, was examined in the clinic, Feb. 4, 1920. Eleven months before, while pregnant, she had had moderate hematuria for one week. Three months later she was delivered of a normal baby. Ten days later she passed a small amount of gravel with severe pain. She was cystoscoped by her home physician who told her that she had a papilloma of the bladder. He fulgurated the growth nine times in six months. Pain over the lumbar region with swelling of the left thigh and leg appeared three months before examination. The pain had been very severe and hematuria marked during the last week.

Physical examination revealed discrete, firm, movable, enlarged glands above the clavicle, in the left iliac region, and in the abdominal fat. A mass $2 \mathrm{~cm}$. by $6 \mathrm{~cm}$. was felt through the vagina in the region of the bladder. On cystoscopic examination a flat necrotic mass was found spread over the left base, left ureteral orifice, and anterior wall of the bladder. The metastases and local condition obviously made the growth inoperable. The patient rapidly became weaker and died five months later.

Examination of a specimen removed during the cystoscopic examination revealed squamous-cell carcinoma of a high degree of malignancy. The cells were large and irregular with active nuclei. There was practically no differentiation, the cells showing only a slight tendency toward cornification and circular disposition.

CASE 5 (313258).-Mrs. G. D. K., aged 47, was examined in the clinic, April 21,1920 . She had been troubled with slight incontinence, which started following childbirth twenty-nine years before. Two unsuccessful attempts had been made to repair her urethra, one eighteen years before, the other four years before. She had not had hematuria or dysuria, but during the last year incontinence had increased with some frequency.

On examination a lacerated perineum and urine dripping from the urethra were found. A firm, fixed mass $10 \mathrm{~cm}$. in diameter was palpated in the region of the bladder. Cystoscopy revealed a tumor involving the entire bladder except the anterior wall. An exploratory operation was performed, and 720 mg. hours of radium given. The bladder and surrounding tissues were extensively involved in the growth. The patient did not recover her strength after the operation and died four months later.

The specimen removed was gray, firm, and compact. It was markedly fibrous throughout. Areas of complete differentiation alternated with sections of malignant tumor cells. In the latter areas the cells were large, well formed and packed closely, projecting in finger-like masses into the surrounding tissue. In some areas hyaline and cystic degeneration of individual cells was found (Fig. 6). Areas of round cells were quite numerous.

CASE, 6 (332791).-Mr. W. C., aged 67, came to the clinic, Sept. 6, 1920. He complained of weakness and loss of weight of one year's duration. He had lost 90 pounds, mainly during the last three months, and had had dysuria, frequency, and moderate difficulty in micturition. For three weeks he had complained of a sense of discomfort over the pubes.

The prostate was found to be enlarged, irregular, firm, and tender. The roentgenograms contained a shadow in the region of the bladder $5 \mathrm{~cm}$. by $6 \mathrm{~cm}$. An exploratory operation was performed and a rough, flinty stone corresponding to the shadow was removed. The entire wall of the bladder was covered with a soft, grayish tumor. Large masses of the growth were scooped out and the bladder closed loosely around a tube. The patient died two days later. At necropsy, bilateral obstruction of the ureter was found. On the left side was 
a pyonephrotic kidney with multiple abscesses, and on the right pyonephrosis with atrophy of the kidney. The wall of the bladder was infiltrated with a grayish tumor; on the posterior superior wall was a diverticulum $4 \mathrm{~cm}$. in diameter. A stone $2 \mathrm{~cm}$. by $5 \mathrm{~cm}$. was found in the prostatic urethra.

Histologic examination of the growth revealed almost complete cellular differentiation; the tumor was a mass of hyalinized tissue. The cornification had taken place in long bands and multiple large rouleaux with only scattered areas of flattened tumor cells. Throughout the cornified areas were many small deposits of calcareous degeneration. Cleavage lines were easily seen, especially in areas where the formation was separated during the preparation of the specimen (Figs. 7 and 8 ).

\section{COMMENT}

Three of the six patients were seen in an operable condition an arerage of three months after the first appearance of symptoms. One of these had a recurrence four months after operation, and died eight months later; one died six months after operation, and one, the only patient who did not die from the disease, is living and well nine years after operation. The other three patients had inoperable tumors. In the inoperable cases, there had been symptoms referable to the carcinoma for an average of twelve months.

Two of the six patients had histories of urinary trouble with undoubted cystitis for more than twenty-eight years. This corresponds to the preoperative history of patients with leukoplakia and may represent such a preexisting condition, the aggravation or exacerbation of symptoms indicating the onset of malignancy. In only one patient (Case 6) was the tumor complicated by stone formation. The extreme hyalinization pointed to a long-standing condition, possibly a simple epidermization, even though the period of symptoms had been short. It is remarkable that with such an extensive local growth there were no metastases. This is probably due to the low incidence of metastasis from tumors of such a high degree of cellular differentiation.

The average age of the patients was 46 years, strikingly lower than the general average age of patients with carcinoma of the bladder. The incidence of sex, four women and two men, is also exceptional and contrary to the usual occurrence in which the male outnumbers the female three or four to one.

Case 1 indicates that a permanent cure is possible. The tumor in this case was highly malignant. An early resection was successful in spite of the local extension and the extreme malignancy of the tumor.

In most cases the insidious onset and the rapidity of the growth make squamous-cell tumor of the bladder an exceptionally dangerous disease. 


\section{SUM MARY}

1. Under certain conditions, such as trauma and infection, the mucosa lining the urinary tract undergoes extensive epidermization.

2. These areas of metaplasia, or, as they are termed, leukoplakia, have a predisposition to form squamous-cell carcinomas of a very high degree of malignancy.

3. Six cases of squamous-cell carcinoma of the bladder are reported; five of the patients died shortly after the disease was discovered. 